\title{
Reproducible Microwave-Assisted Acid Hydrolysis of Proteins Using a Household Microwave Oven and Its Combination with LC-ESI MS/MS for Mapping Protein Sequences and Modifications
}

\author{
Nan Wang and Liang Li \\ Department of Chemistry, University of Alberta, Edmonton, Alberta, Canada
}

\begin{abstract}
A new set-up for microwave-assisted acid hydrolysis (MAAH) with high efficiency and reproducibility to degrade proteins into peptides for mass spectrometry analysis is described. It is based on the use of an inexpensive domestic microwave oven and can be used for low volume protein solution digestion. This set-up has been combined with liquid chromatography electrospray ionization quadrupole time-of-flight mass spectrometry (LC-ESI QTOF MS) for mapping protein sequences and characterizing phosphoproteins. It is demonstrated that for bovine serum albumin (BSA), with a molecular mass of about 67,000 Da, 1292 peptides (669 unique sequences) can be detected from a $2 \mu \mathrm{g}$ hydrolysate generated by trifluoroacetic acid (TFA) MAAH. These peptides cover the entire protein sequence, allowing the identification of an amino acid substitution in a natural variant of BSA. It is shown that for a simple phosphoprotein containing one phosphoform, $\beta$-casein, direct analysis of the hydrolysate generates a comprehensive peptide map that can be used to identify all five known phosphorylation sites. For characterizing a complex phosphoprotein consisting of different phosphoforms with varying numbers of phosphate groups and/or phosphorylation sites, such as bovine $\alpha_{\mathrm{S} 1}$-casein, immobilized metal-ion affinity chromatography (IMAC) is used to enrich the phosphopeptides from the hydrolysate, followed by LC-ESI MS analysis. The MS/MS data generated from the initial hydrolysate and the phosphopeptide-enriched fraction, in combination with MS analysis of the intact protein sample, allow us to reveal the presence of three different phosphoforms of bovine $\alpha_{\mathrm{S} 1}$-casein and assign the phosphorylation sites to each phosphoform with high confidence. (J Am Soc Mass Spectrom 2010, 21, 1573-1587) (c) 2010 American Society for Mass Spectrometry
\end{abstract}

$\mathrm{P}$ rotein sequence mapping is commonly used to study post-translational modifications of a protein or amino acid substitutions from point mutations in the genome. Ideally, the entire amino acid sequence of a protein should be mapped to pinpoint where a modified amino acid or a substitution is located. Mass spectrometry (MS) has become an indispensable tool for protein sequence mapping [1,2]. This is usually done by using a top-down or a bottom-up proteomic approach [1-12]. In the top-down method, a protein ion is dissociated in a tandem mass spectrometer (MS/MS) and the fragment ions generated are interpreted to generate a stretch of amino acid sequence information. Sequence coverage by this method is dependent on the nature of the protein, ranging from a few residues to a full sequence [12]. In general, full sequence information is difficult to obtain for a protein with molec-

Address reprint requests to Professor L. Li, Department of Chemistry, University of Alberta, E3-44 Chemistry Building, Edmonton, Alberta T6G 2G2, Canada. E-mail: Liang.Li@ualberta.ca ular mass of $>20,000 \mathrm{Da}$ [12]. The bottom-up approach is a robust method for protein identification based on sequencing by MS/MS one or more peptides generated by chemical or enzymatic degradation of a protein. For a protein digest, such as that produced by trypsin digestion, one or a few peptides are sequenced, resulting in only a partial coverage of the protein sequence. To increase the sequence coverage of a protein by the bottom-up method, multiple enzyme or chemical degradation experiments can be done to generate complementary sequence information. However, this is a time-consuming process and there is no guarantee that the peptides produced from the multiple digestions will cover the entire sequence of a protein. In some cases, the combination of top-down and bottom-up methods is used to increase sequence coverage $[4,7,12]$.

An alternative MS technique for protein sequence mapping is based on the use of microwave-assisted acid hydrolysis (MAAH) to degrade the protein into peptides, followed by MS analysis [13-16]. When a strong acid, such as $6 \mathrm{M} \mathrm{HCl}$ is used for MAAH and a 
microwave irradiation time is kept at less than 2 min, the hydrolysate generated from a protein consists of mainly terminal peptides $[13,16]$. Analysis of the peptide mixture by matrix-assisted laser desorption/ ionization (MALDI) time-of-flight (TOF) MS results in a spectrum composed of peaks from both the $\mathrm{N}$ - and C-terminal peptides. Deconvolution of these peaks into two series of peptide peaks and determination of the mass difference from adjacent peaks of $\mathrm{N}$ - or C-terminal peptide series (i.e., sequence ladders) allows the protein sequence to be mapped. A complete sequence can be read from a protein of up to 18,000 Da (e.g., human hemoglobin). The sensitivity of MALDI-TOF at the high mass region determines the upper mass limit of a protein that can be fully sequenced. Even with state-of-the-art TOF instruments, the detection sensitivity at $>18,000 \mathrm{Da}$ is not sufficient to generate any useful signals from a protein hydrolysate. Thus, for higher mass proteins, only partial sequences from the $\mathrm{N}$ - and C-terminus can be obtained by this $\mathrm{HCl}$ MAAH technique.

If $\mathrm{HCl}$ is replaced by $25 \%$ trifluoroacetic acid (TFA) for MAAH and the irradiation time is increased to 8 to $10 \mathrm{~min}$, proteins can be degraded into small peptides [14]. These small peptides have molecular masses of up to about 3,000 Da that are ideal sizes for MS/MS using collision-induced dissociation (CID) in a tandem mass spectrometer. These peptides consist of both terminal and internal peptides and, thus, unambiguous sequence ladder information cannot be obtained by MS analysis. However, LC-MS/MS analysis of the hydrolysate, followed by a protein database search, can result in identification of these peptides. In the work by Zhong et al., it was shown that the sequence of bacteriorhodopsin $(24,000 \mathrm{Da})$ could be mapped with 95\% coverage [14]. This original work was carried out using LC-MALDI MS/MS in a quadrupole time-of-flight (QTOF) mass spectrometer.

Recently, microwave-assisted chemistry has been used in a wide range of protein sample preparations for proteome analysis [15, 17-29]. Dedicated microwave ovens designed for handling low volumes of samples are now commercially available [15]. Alternatively, an inexpensive household microwave oven can be used. However, one major concern in using this type of oven is whether it can generate reproducible results for mass spectrometric analysis. In this work, we report a simple and robust technique for carrying out MAAH using a household microwave oven and demonstrate that peptides can be generated with high reproducibility. This MAAH technique was then combined with nano-LC electrospray ionization (ESI) QTOF MS for sensitive sequencing of the resultant peptides. We demonstrate that using one-dimensional (1D) LC-ESI MS/MS for the analysis of TFA MAAH hydrolysates, bovine serum albumin (BSA) $(66,500 \mathrm{Da})$ could be sequence-mapped with almost complete coverage, allowing the detection of a BSA variant with one amino acid substitution. In addition, phosphorylation sites of bovine $\beta$-casein could be completely mapped. In characterizing a more complex sample, bovine $\alpha$-casein, we developed and applied a strategy of analyzing the hydrolysate before and after phosphopeptide enrichment by immobilized metal-ion affinity chromatography (IMAC) to provide a detailed sequence map as well as comprehensive phosphorylation site coverage. Three phosphoforms of bovine $\alpha$-casein were identified with their phosphorylation sites determined.

\section{Experimental}

\section{Chemicals and Reagents}

Dithiothreitol (DTT), trifluoroacetic acid (TFA), LC-MS grade formic acid, bovine serum albumin, $\beta$-casein, $\alpha$-casein, and other protein standards were purchased from Sigma-Aldrich Canada (Markham, ON, Canada). LC-MS grade water, acetonitrile $(\mathrm{ACN})$ and the micro centrifuge tube holders were from Fisher Scientific Canada (Edmonton, Canada).

\section{Microwave-Assisted Acid Hydrolysis}

Ten $\mu \mathrm{L}(1 \mu \mathrm{g} / \mu \mathrm{L})$ of the protein solution was mixed with an equal volume of $20 \mathrm{mM}$ DTT in a $1.5 \mathrm{~mL}$ polypropylene centrifuge vial and incubated at $60^{\circ} \mathrm{C}$ for $20 \mathrm{~min}$. Twenty $\mu \mathrm{L} \mathrm{50 \%} \mathrm{(vol/vol)} \mathrm{TFA} \mathrm{was} \mathrm{added} \mathrm{to}$ the sample solution after incubation. The vial was then capped, sealed with Teflon tape, and placed in a domestic $900 \mathrm{~W}(2450 \mathrm{MHz})$ microwave oven (Panasonic, London Drugs, Edmonton, Canada). For the traditional microwave method, $100 \mathrm{~mL}$ of water in a loosely covered container was placed beside the sample vial to absorb extra microwave energy [13, 14]. For the new and improved microwave method, the sample vial was placed on a Scienceware round bubble rack (Fisher Scientific, Edmonton, Canada) and floated in a plastic beaker, which contained $100 \mathrm{~mL}$ of water (see Supplemental Figure S1, which can be found in the electronic version of this article). The beaker was placed in the center of the rotating plate in the microwave oven. For the location dependence study (see Results and Discussion and Supplemental Figure S2), the plastic beaker was placed off-center in the microwave so that the sample positions were randomly distributed in the microwave oven. The sample volume used for MAAH $(40 \mu \mathrm{L})$ was limited and thus the relatively large sample vial capped and sealed with Teflon tape could tolerate the vapor pressure produced when the sample was microwave irradiated. After microwave irradiation for a period indicated in the Results and Discussion, the sample vial was taken from the microwave oven and the solution was dried in a SpeedVac to remove the acid. The protein digest was re-suspended in $50 \mu \mathrm{L}$ of $0.1 \%$ formic acid aqueous solution and centrifuged at 14,000 rpm for $5 \mathrm{~min}$ to remove any possible residual particles. A portion of the hydrolysate was injected into the LC-MS/MS system for separation and sequencing. 
The total sample preparation time in MAAH is up to $54 \mathrm{~min}$, including $20 \mathrm{~min}$ for DTT reduction, $1 \mathrm{~min}$ for adding acid and sealing the vial, up to $10 \mathrm{~min}$ for MAAH, $20 \mathrm{~min}$ for removing the acid, $1 \mathrm{~min}$ for reconstituting the hydrolysate in $0.1 \%$ formic acid, and $2 \mathrm{~min}$ for centrifugation of the resultant sample that is ready for LC-MS/MS.

\section{IMAC Enrichment of Phosphopeptides}

For the analysis of the $\alpha$-casein sample, a portion of the hydrolysate was subjected to IMAC phosphopeptide enrichment using Fe-IMAC resin (Phos-Select iron affinity gel; Sigma, Ontario, Canada). The SpeedVac dried hydrolysate sample was re-suspended in 30\% acetonitrile (ACN) mixed with $250 \mathrm{mM}$ acetic acid and the peptides were loaded onto the Fe-IMAC resin. The resin was washed three times with $30 \%$ acetonitrile $(\mathrm{ACN}) / 250 \mathrm{mM}$ acetic acid, two times with water after $2 \mathrm{~h}$ incubation at ambient temperature. The phosphopeptides were then released from the resin with $400 \mathrm{mM}$ ammonium hydroxide.

\section{LC-ESI QTOF MS and MS/MS}

Hydrolysates of protein solutions were analyzed using a QTOF Premier mass spectrometer (Waters, Manchester, U.K.) equipped with a nanoACQUITY Ultra Performance LC system (Waters, Milford, MA, USA) [21, 30]. In brief, $5 \mu \mathrm{L}$ of peptide solution was injected onto a 75 $\mu \mathrm{m} \times 150 \mathrm{~mm}$ Atlantis dC18 column with $3 \mu \mathrm{m}$ particle size (Waters). Solvent A consisted of $0.1 \%$ formic acid in water, and Solvent B consisted of $0.1 \%$ formic acid in ACN. Peptides were first separated using $120 \mathrm{~min}$ gradients $(2 \%-6 \%$ Solvent B for $2 \mathrm{~min}, 6 \%-25 \%$ Solvent B for $95 \mathrm{~min}, 30 \%-50 \%$ Solvent B for $10 \mathrm{~min}, 50 \%-90 \%$ Solvent B for $10 \mathrm{~min}, 90 \%-5 \%$ Solvent B for $5 \mathrm{~min}$; the column was pre-equilibrated at $2 \%$ Solvent B for 20 min) and electrosprayed into the mass spectrometer (fitted with a nanoLockSpray source) at a flow rate of $300 \mathrm{~nL} / \mathrm{min}$. Mass spectra were acquired from $\mathrm{m} / \mathrm{z} 300$ to 1600 for $0.8 \mathrm{~s}$, followed by four data-dependent MS/MS scans from $m / z 50-1900$ for $0.8 \mathrm{~s}$ each. The collision energy used to perform MS/MS was varied according to the mass and charge state of the eluting peptide. Leucine enkephalin and (Glu1)-fibrinopeptide $B$, a mixed mass calibrant (i.e., lock-mass), was infused at a rate of $300 \mathrm{~nL} / \mathrm{min}$, and an MS scan was acquired for $1 \mathrm{~s}$ every $1 \mathrm{~min}$ throughout the run.

\section{Protein Database Search}

Raw MS and MS/MS data were lock-mass-corrected, de-isotoped, and converted to peak list files by ProteinLynx Global Server 2.3 (Waters). Peptide sequences were identified via automated database searching of peak list files using the MASCOT search program (http:// www.matrixscience.com). Database searches were restricted to the protein sequence of the corresponding protein downloaded from the SwissProt database. The following search parameters were selected for all database searching: enzyme, nonspecified; missed cleavages, 1 ; peptide tolerance, $\pm 30 \mathrm{ppm} ; \mathrm{MS} / \mathrm{MS}$ tolerance, $0.2 \mathrm{Da}$; peptide charge, $(1+, 2+$, and $3+)$; variable modifications, oxidation $(\mathrm{M})$, deamidation of asparagine and glutamine. The search results, including unique peptide sequences, ion score, MASCOT threshold score for identity, calculated molecular mass of the peptide, and the difference (error) between the experimental and calculated masses were extracted to Excel files. All the identified peptides with scores lower than the MASCOT identity threshold scores for identity were then deleted from the list. For the phosphopeptide matches, manual inspection of the MS/MS spectra and peak assignments was performed to confirm the phosphorylation site assignment. To increase the confidence of phosphopeptide identification and site assignment, evidence of three or more peaks from the phosphorylated fragment ions must be present in a MS/MS spectrum for it to be considered to be a positive match. This manual inspection process was a manageable task as many phosphopeptides containing a phosphorylation site shared similar sequences with differences in a few amino acids at the terminus (i.e., phosphopeptide ladders). Future work on automation of protein modification assignment based on the peptide ladders and sequences generated should greatly facilitate data interpretation related to the TFA LC-MS/MS technique.

\section{Results and Discussion}

\section{New Setup for MAAH}

LC-ESI MS/MS is a sensitive technique for sequencing peptides and, thus, small variation of the peptide composition in the hydrolysate generated from the TFA MAAH process can affect the final results. Household microwave ovens are known to have "hot" spots due to unevenly distributed microwave radiation [31, 32]. To examine the effect of sample location inside the microwave oven on data reproducibility, we placed four vials of a BSA solution containing TFA at different locations on the rotating plate (see Supplemental Figure S2A for illustration) and a beaker containing $100 \mathrm{~mL}$ of water beside the sample rack. After microwave irradiation for 10 min, the samples were taken out, processed, and analyzed by LC-ESI QTOF MS. Table 1 summarizes the number of peptides detected and the average MASCOT scores of peptide identification for the four samples. Clearly, the numbers and scores are different, indicating that sample location inside the oven affects the results.

Both heat and microwave radiation play important roles in determining the reaction outcome in microwaveassisted chemistry, although the exact role of microwave radiation is still unknown [33-36]. It has been shown that direct heating of a protein solution mixed with an acid without microwave irradiation may result in protein aggregation, preventing the complete hydrolysis of the sample $[13,14]$. This is particularly true for hydrophobic membrane proteins $[14,21]$. Furthermore, a protein sam- 
Table 1. Summary of the number and the average MASCOT matching score of peptides identified from LC-ESI QTOF MS analysis of individual hydrolysates. Protein samples were placed at different locations inside a domestic microwave oven (Supplemental Figure S2); and subjected to TFA MAAH using the traditional and new microwave set-ups

\begin{tabular}{lcccc}
\hline & Average number of unique peptides & Sequence coverage (\%) & Total peptide score & Average peptide score \\
\hline \hline Old set-up & & & & \\
Position a & $437 \pm 11$ & $87.1 \pm 0.3$ & $30883 \pm 1164$ & $40.2 \pm 0.2$ \\
Position b & $299 \pm 4$ & $83.6 \pm 0.1$ & $17979 \pm 369$ & $36.8 \pm 0.2$ \\
Position c & $410 \pm 8$ & $85.5 \pm 1.3$ & $26870 \pm 237$ & $39.0 \pm 1.0$ \\
Position d & $388 \pm 5$ & $86.1 \pm 1.8$ & $24821 \pm 907$ & $38.8 \pm 0.6$ \\
New set-up & & & & \\
Position a & $682 \pm 16$ & $98.5 \pm 0.1$ & $54154 \pm 669$ & $44.0 \pm 0.3$ \\
Position b & $702 \pm 21$ & $98.6 \pm 0.1$ & $54744 \pm 987$ & $43.7 \pm 0.2$ \\
Position c & $648 \pm 2$ & $98.3 \pm 0.3$ & $52437 \pm 611$ & $43.7 \pm 0.3$ \\
Position d & $698 \pm 12$ & $98.1 \pm 0.7$ & $54125 \pm 341$ & $43.7 \pm 0.1$ \\
\hline
\end{tabular}

ple does not need to be completely dissolved in TFA for MAAH - merely suspending the protein sample in TFA is sufficient for acid hydrolysis [21, 37]. However, in the traditional microwave experiment using a household microwave oven $[13,14,38]$, a sample vial containing a low volume of solution $(40 \mu \mathrm{L})$ only absorbs a small fraction of the microwave energy. The solution temperatures in the vials placed at different locations might be different, resulting in different rates of hydrolysis. To create more uniform heating, we placed the sample vial inside a beaker filled with water (see the schematic shown in Supplemental Figure S1). The relatively larger volume of water in the beaker was heated to boiling during the microwave process. The sample solution placed inside a sealed sample vial appeared not to be boiled to a great extent, as the majority of the solution still remained at the bottom of the sample vial after the microwave experiment. The pressure inside the vial might be greater than one atmosphere, thus increasing the boiling point of the solution. The solution temperature in the vial is unknown, as we could not measure the temperature using the simple set-up.

Almost identical ion chromatograms of the BSA hydrolysates were produced by using this new microwave heating method from the samples at different locations (see Supplemental Figure S2B for sample location illustration). For comparison, the numbers of peptides and average MASCOT scores from these LC-ESI MS/MS runs are listed in Table 1. The numbers and scores generated for these four samples are almost the same. We also found that day-to-day reproducibility was very good using this method. From this work, we can conclude that acid hydrolysis can be reproducibly carried out using an inexpensive household microwave oven with the new set-up shown in Supplemental Figure S1.

\section{Complete Sequencing of BSA and Identification of an Amino Acid Substitution}

The sequence coverage of the hydrolysate of BSA was investigated. The entire sequence of BSA, as shown in Supplemental Figure S3, was covered by the peptides detected from the LC-ESI MS/MS analysis of the hydrolysate. In our initial MS/MS search using the
SwissProt database, we missed one amino acid, residue 214, which was listed as A (alanine) in this database. This was quite odd, as all other amino acids were covered by the peptides detected. After searching the literature, it was found that this amino acid has been documented to be $\mathrm{T}$ (threonine), a natural variant site [see SwissProt database, P02769 (ALBU_BOVIN)] [39]. In our experiment, we positively confirmed that this sample was BSA with $\mathrm{T}$ in residue 214. This confirmation is illustrated in the three MS/MS spectra shown in Figure 1. A MASCOT database search against the BSA sequence with T-214 resulted in the matches of the mass spectra to the three peptide sequences shown in Figure 1. In contrast, when $\mathrm{T}$ was replaced by A, no matches were found. Comparison of the three MS/MS spectra shown in Figure 1 also provides unambiguous sequence assignment to the last few amino acids in the Cterminus. For example, the fragment ions, y11 in Figure $1 a, y 12$ in Figure 1b, and y13 in Figure 1c, belong to the same series that together indicate the extension of the sequence from ACLLPKIETMREKVL, to ACLLPKIETMREKVLT, then to ACLLPKIETMREKVLTS.

There were in total 1292 peptides (669 of them were unique in sequence) detected from the BSA hydrolysate using LC-ESI MS/MS. The peptides detected and their sequences along with MASCOT scores are listed in Supplemental Table S1. These peptides are mainly from the internal peptides produced during the MAAH process. The molecular masses of peptides range from 521 to 4453 Da with charge states of +1 (eight peptides), +2 (217 peptides), +3 (209 peptides), and +4 (235 peptides). Although many of the peptides do not contain arginine or lysine at the $\mathrm{C}$-terminus as in the case of tryptic peptides, these peptide ions can be readily dissociated, generating sufficiently high quality MS/MS spectra for database searching. For this dataset, there appears to be some preferential detection of peptides with glycine or alanine at either $\mathrm{C}$ - or N-terminus. Both hydrolysis and ionization processes may contribute to the biased detection. More work is required to understand the specificity, if any, in bond breakage during the acid hydrolysis using TFA. In addition, it would be interesting to compare the ionization efficiency and MS/MS spectral quality for da- 

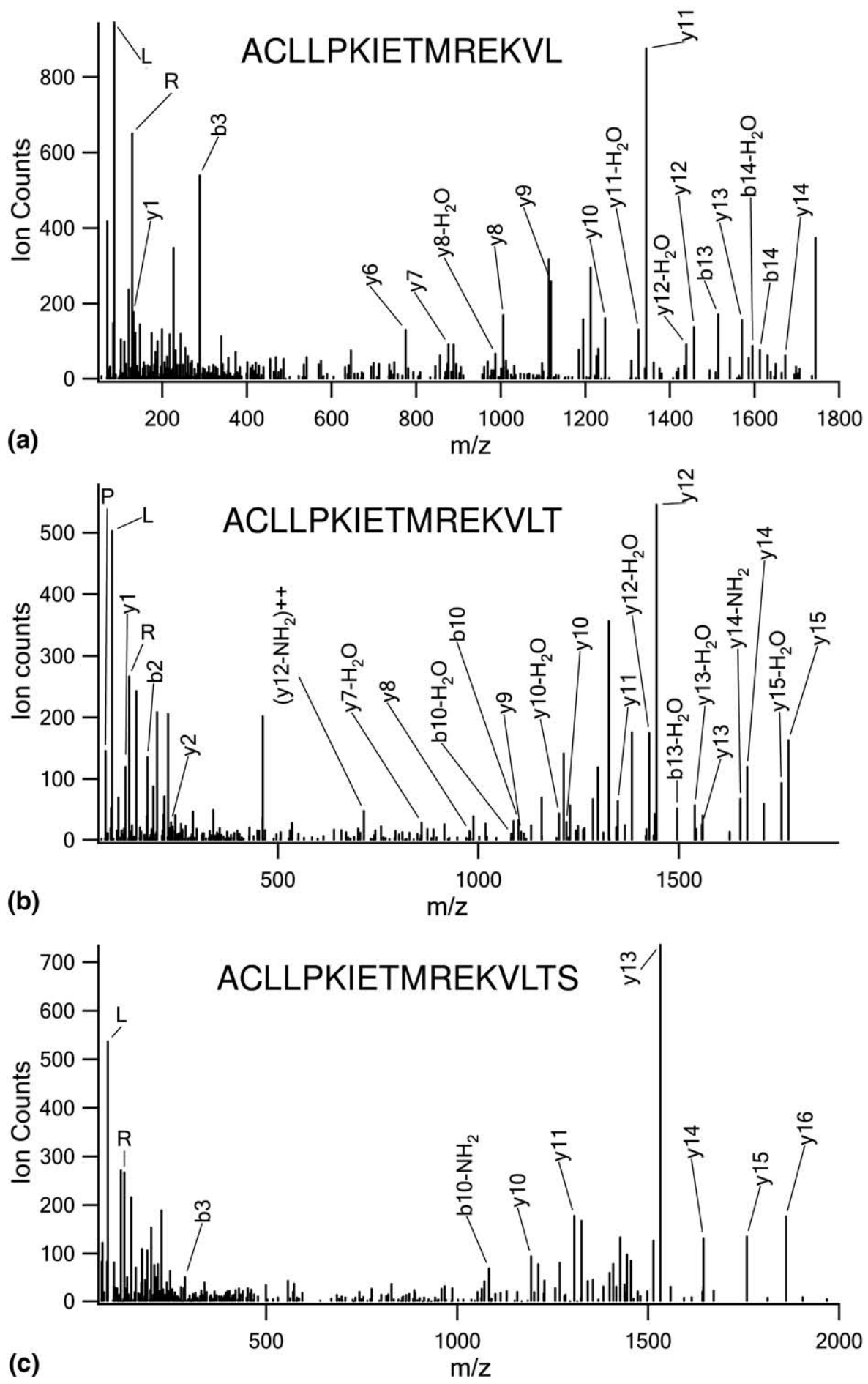

Figure 1. MS/MS spectra of three peptides matched with sequences near residue 214, a natural variant site of BSA. The matched peptide sequences are shown in the spectra along with the fragment ion peak assignments.

tabase search of the peptides with no or internal arginine or lysine to those with terminal arginine or lysine.

\section{Database and MASCOT Search}

In a conventional proteomic analysis workflow, all sequences of proteins of the proteome of interest are entered into the database for MS/MS spectral search using search engines such as MASCOT. However, in this work, only the protein(s) of interest (e.g., BSA) was entered into the database. This was done after the following careful considerations.

We found that compared with database search using the BSA sequence only, the MASCOT score of each 
MS/MS match did not change after the BSA sequence was appended to a proteome database, e.g., the E. coli proteome consisting of over 4300 sequences. Thus, the main parameter for gauging the quality of the spectrum, i.e., MASCOT score, was not affected by the database size.

To determine how database size would affect the search results, we did another comparison where the search results of the MS/MS spectra generated from the LC-MS/MS analysis of 200 fmol BSA tryptic digest were produced by using the database of BSA only or BSA plus the E. coli proteome. Carbamidomethyl (C) was selected as fixed modification and oxidation (M) was selected as variable modification for database search. All the other search parameters were the same as the ones chosen for MAAH data. In total, 71 tryptic peptides were matched using the BSA sequence alone with a protein sequence coverage of $63 \%$, while 70 tryptic peptides and $63 \%$ coverage were found using the database of BSA plus the E. coli proteome. The identity threshold was 13 when the database contained only the BSA sequence. This threshold increased slightly to 14 when BSA plus E. coli was used. Overall, there was little effect of database size on MASCOT search results for the tryptic digest of BSA.

However, due to the nonspecific cleavage feature of the acid hydrolysis process, no enzyme parameter was chosen for MASCOT search of the data acquired from the MAAH experiment. This selection, although correct, greatly increased the MASCOT identity threshold. The same BSA tryptic digest LC-MS/MS data were searched against the BSA protein alone without choosing any specific enzyme. The identity threshold for all the peptides stayed at 13. In total, 108 peptides were matched, covering $65 \%$ of the protein sequence, by searching against BSA (some semi-tryptic peptides were identified and manually confirmed, likely due to the presence of degraded fragments of BSA in this sample and/or non-specific cleavage during trypsin digestion). However, when searched against BSA plus $E$. coli database, we found that the identity threshold increased to 34 . Both the number of matched peptides and sequence coverage dropped significantly to 75 peptides and $55 \%$, respectively. As all other parameters stayed the same except the database was changed, the MASCOT score for each MS/MS spectrum stayed the same. Again the parameter for gauging the quality of the spectral match was not affected by the size of the database.

We also compared the search results generated using the two databases mentioned above for the MAAH data of BSA. Using BSA alone for database search, as indicated earlier, there were in total 1292 peptides (669 unique sequences) detected from the BSA hydrolysate, representing $100 \%$ protein sequence coverage. Using the same dataset searching against the BSA plus E. coli proteome database, we found 632 peptides and 407 of them were unique, representing $96 \%$ coverage. The loss of 262 unique peptides was due to the significant increase of peptide identity threshold; the scores of all peptide matches stayed the same, but the identity threshold increased from 16 to about 42 .

The above results indicate that the MASCOT scoring algorithm places a very heavy weight on enzyme specificity (the actual weighing factors are unknown). This is perhaps justified as random matches of peptides without the constraint of specific terminal amino acids are expected to increase as the database size increases. The use of a very high threshold score minimizes the possibility of false positive match. However, this is done at the expense of sensitivity, i.e., many matches with scores between 16 and 42 may be falsely eliminated. Indeed, in the BSA MAAH dataset, manual inspection of the MS/MS spectra with matching scores above a threshold set by searching the BSA alone (i.e., a threshold of 16) suggested that these spectra were correctly matched. In the MAAH database, manual MS/MS interpretation can be readily done by examining the peptide ladders; spectra of peptide ladders with a stretch of common amino acid sequence share similar fragmentation patterns in the product ion spectra (see Figure 1 as an example). Thus, we conclude that the use of a database consisting of one or a few proteins for MASCOT search is justified for the LC-MS/MS data generated from the hydrolysate of one or a few proteins, and is a preferred approach, compared with the use of a database constructed by appending the protein(s) of interest to a proteome database.

\section{Optimization of MAAH}

Acid type and concentration have been investigated in the previous study and the use of $25 \%$ TFA was found to be optimal for generating peptides for MS/MS [14]. With the possibility of generating reproducible data by using the new microwave hydrolysis set-up, we can now investigate the effect of microwave irradiation time on the peptide identification results. A series of LC-ESI MS ion chromatograms of the BSA hydrolysates prepared by using different irradiation times (i.e., 2.5, 5, 7.5, and $10 \mathrm{~min}$ ) were obtained (see Supplemental Figure S4). The base peak ion chromatograms, particularly the relative peak intensities of the late eluting peptides (between 85 and $105 \mathrm{~min}$ ) compared with the early eluting peptides, are different, indicating that the peptide compositions of the hydrolysates were noticeably different. Generally, larger peptides are found in the late eluting chromatographic peaks (i.e., retention time $>50 \mathrm{~min}$ ) and smaller peptides tend to elute earlier in the reversed-phase separation, although charge states and other interaction forces affect the retention properties of peptides. When the irradiation time increases, shorter peptides are generated. This can be seen by comparing the relative peak intensities of the ion chromatograms, e.g., Figure S4A versus S4C. However, the chromatograms shown in Figure S4C (7.5 min irradiation) and S4D (10 min irradiation) appear to be similar. To investigate this trend further, we can compare the number 
of unique peptides identified and sequence coverage obtained from the LC-ESI MS/MS chromatograms shown in Figure S4. The number of identified peptides and sequence coverage were 515 and $88.9 \%$ for the $2.5-\mathrm{min}$ run (the missed amino acids were ${ }^{200}$ CLLPKIETMREKVLTSSARQRLRC ${ }^{223},{ }^{247}$ PKAE $^{250},{ }^{475}$ YLSLILNRLCVL$\mathrm{HEK}^{489}$, ${ }^{536} \mathrm{ICTLPD}^{541}$, ${ }^{558}{ }^{\mathrm{HKPKATEEQLKTVMEN}}{ }^{573}$ ), 586 and $97.6 \%$ for the 5-min run (the missed amino acids were ${ }^{542}$ TEKQIKKQ $^{549},{ }^{563}$ TEEQLK $^{568}$ ), 669 and $100 \%$ for the 7.5 -min run, and 672 and $99.5 \%$ for the $10-\mathrm{min}$ run (the missed amino acids were $\left.\mathrm{I}^{536}, \mathrm{C}^{537}, \mathrm{D}^{586}\right)$. This BSA work, along with studies of other proteins, such as insulin, ubiquitin, cytochrome $c$, and myoglobins (data not shown), indicates that irradiation time of between 7.5 and $10 \mathrm{~min}$ is optimal in generating the peptides for LC-ESI MS/MS. Note that these results were obtained from a $900 \mathrm{~W}$ household microwave oven. For a higher power microwave oven, the hydrolysis time likely needs to be reduced and should be optimized to achieve the best performance. The performance of MAAH was found to be the same in two brands of $900 \mathrm{~W}$ microwave oven, Panasonic and Sunbeam (The Superstore, Edmonton, Canada).

Another set of experiments was carried out to compare the hydrolysis efficiency of MAAH to that of simple heating without microware irradiation where sample vials were placed in boiling water. MALDI-TOF MS analysis of the hydrolysates generated by using different heating times (i.e., 2.5, 5, and $7.5 \mathrm{~min}$ ) showed strong protein signals, indicating that the hydrolysis by heating even at 7.5 min was incomplete, compared with complete hydrolysis in 7.5-min MAAH. In addition, 905 peptides (588 unique ones) were identified from the LC ESI MS/MS analysis of the hydrolysate produced from the 7.5-min boiling experiment, compared with 1292 peptides (669 unique ones) from the 7.5-min MAAH experiment. The 588 unique peptides covered $88 \%$ of the protein sequence, as opposed to almost $100 \%$ coverage in MAAH. These results indicate that simple heating is not as efficient as MAAH for hydrolyzing proteins.

The minimum amount of sample required to generate near complete sequence coverage was investigated using BSA as a standard. The number of peptides identified and sequence coverage were $416 \pm 16$ and $94.0 \% \pm$ $2.7 \%$ (two replicates; the missed amino acids were ${ }^{56} \mathrm{QQC}^{58},{ }^{214} \mathrm{TSSARQRLRC}^{223},{ }^{569} \mathrm{TVME}^{572}$ in run 1 , and ${ }^{52}$ SQYLQQC ${ }^{58},{ }^{200}$ CLLPKIETMREKVLTSSARQR$\mathrm{LRC}^{223},{ }^{268} \mathrm{CCH}^{270}, \mathrm{D}^{474},{ }^{536} \mathrm{ICTLPD}^{541},{ }^{569} \mathrm{TVMEN}^{573}$, ${ }^{586} \mathrm{DKEAC}^{590}$ in run 2) when $0.5 \mu \mathrm{g}$ of the BSA hydrolysate was injected for sequencing, $559 \pm 7$ and $96.8 \% \pm 0.3 \%$ for $1 \mu \mathrm{g}$ injection (the missed amino acids were $\mathrm{Q}^{57}, \mathrm{C}^{58},{ }^{214}$ TSSARQRLRC ${ }^{223},{ }^{268} \mathrm{CCH}^{270}$, ${ }^{536} \mathrm{ICTLPD}^{541}$ in run 1 , and ${ }^{214} \mathrm{TSSARQRLRC}{ }^{223}$, ${ }^{584}{ }^{A D D K E A C}{ }^{590}$ in run 2), $625 \pm 4$ and $97.5 \% \pm 0.8 \%$ for $2 \mu \mathrm{g}$ injection (the missed amino acids were $\mathrm{T}^{214}, \mathrm{~S}^{215}$, ${ }^{268} \mathrm{CCH}^{270}$, ${ }^{586} \mathrm{DKEAC}^{590}$ in run 1 , and ${ }^{214} \mathrm{TSSARQR}-$ $\mathrm{LRC}^{223},{ }^{268} \mathrm{CCH}^{270}, \mathrm{I}^{536}, \mathrm{C}^{537},{ }^{586} \mathrm{DKEAC}^{590}$ in run 2$)$, and $670 \pm 3$ and $99.2 \% \pm 0.8 \%$ for $4 \mu \mathrm{g}$ injection (the missed amino acids were ${ }^{214}$ TSSARQRLRC ${ }^{223}$ in run 1 , and none in run 2). As expected, sequence coverage is reduced when less sample is injected. When the injection amount is equal to or above $1 \mu \mathrm{g}$, sequence coverage of greater than $97 \%$ can be obtained. A few amino acids were occasionally missed in a given run, likely due to the ion suppression effect in ESI, although we cannot rule out the possibility of some of the peptide bonds not being hydrolyzed as efficiently as others.

The above work indicates that TFA MAAH combined with LC-ESI MS/MS can be used to obtain near complete sequence coverage of a protein and thus it is quite suitable for investigating any amino acid sequence variation, such as the case of a natural amino acid variant of BSA. We believe that this technique should work for any size of protein. However, for a protein larger than BSA, more separation at the peptide level (e.g., using 2D-LC, instead of 1D-LC) may be required to identify a greater number of peptides to cover the entire protein sequence. Our work indicates that for a protein size of up to that of BSA, 1D-LC separation combined with ESI MS/MS is sufficient to cover the entire sequence.

\section{Characterization of Bovine $\beta$-Casein Phosphorylation Sites}

A more challenging application of the technique of TFA MAAH LC-ESI MS/MS is in the area of characterizing post-translational modifications (PTMs) of proteins. However, this technique should work well to generate information on PTMs, as it provides near complete sequence coverage of a protein. One example of PTM analysis is shown for the characterization of a phosphoprotein, bovine $\beta$-casein. This protein is known to exist as a single phosphoform containing 5 phosphate groups [40]. It has been widely used as a model protein for MS-related technical and method development aimed at phosphoprotein characterization. For example, trypsin digestion of $\beta$-casein, followed by $\mathrm{Fe}^{3+}$-IMAC enrichment of phosphopeptides and MALDI MS/MS analysis, has been used to detect five phosphopeptides covering the 5 known phosphorylation sites [41]. Titanium dioxide $\left(\mathrm{TiO}_{2}\right)$ has been used as an alternative to enrich phosphopeptides with higher efficiency [42, 43]. Other materials such as zirconium dioxide have also been used to enrich phosphopeptides of $\beta$-casein digest [44]. However, the number of peptides detected from a tryptic digest is often limited and thus it is very difficult to cover the entire sequence, even for a small protein such as $\beta$-casein [45]. This is a well recognized issue related to the bottom-up proteome analysis method [9]. Bovine $\beta$-casein has been studied by using the topdown method with collisionally induced dissociation (CID) and electron capture dissociation (ECD) [46]. ECD, which was shown to be superior to CID, fragmented 87 of the 208 backbone bonds, representing $42 \%$ sequence coverage. These fragment ions allowed the positive identification of one phosphorylation site (Ser- 
15) and narrowed down the other phosphorylation sites to certain sequence regions [46]. Plasma ECD has been shown to fragment 126 of the 208 backbone bonds, which covered the five phosphorylation sites [47]. Bovine $\beta$-casein has also been subjected to middle-down CID MS/MS analysis where Lys-C was used as an enzyme to produce peptides of middle size, 5000 to 10,000 Da [45]. Combined with trypsin digestion, sequence coverage of $97 \%$ was attained. Using both $\mathrm{MS}^{2}$ and $\mathrm{MS}^{3}$ in an ion trap FT-MS for sequencing small and middle sizes of peptides, five known phosphorylation sites could be identified [45].

In our work, a total of 3182 MS/MS spectra were collected from the injection of about $2 \mu \mathrm{g}$ of bovine $\beta$-casein hydrolysate onto LC-ESI MS/MS, resulting in the matching of 1527 peptides with the protein sequence. Among them, 977 peptides were unique ones with or without modifications. These peptides and their sequences along with MASCOT scores are listed in Supplemental Table S2. Note that, in Table S2, there are many deamidated peptides. Peptide deamidation was induced by the MAAH process. In some cases, a unique peptide sequence can have zero, one, or two deamidation sites. It was found that the concurrent presence of two or three peptides with different deamidation sites was very useful for confirming peptide sequence assignments. Figure 2 shows the protein sequence and the sequences of the detected phosphopeptides that are underlined. The 977 peptides detected cover the entire sequence of $\beta$-casein. Among them, 36 peptides are phosphopeptides. As Figure 2 shows, five sites out of

\section{$\beta$-casein (P02666)}

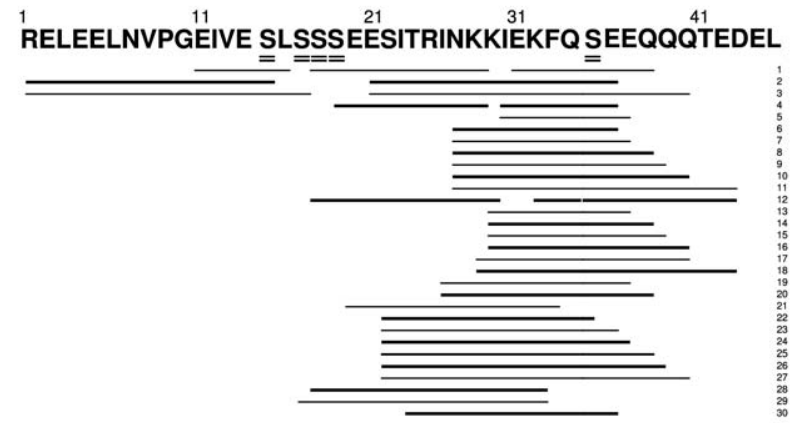

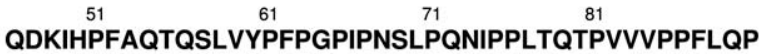 $\stackrel{91}{\text { EVMGVSKVKEAMAPKHKEMPFPKYPVEPFTESQSLTLTDVENLHL }} \stackrel{121}{131}$ PLPLLQSWMHQPHQPLPPTVMFPPQSVLSLSQSKVLPVPQKAVPY \\ $\stackrel{181}{\text { PQRDMPIQAFLLYQEPVLGPVRGPFPIIV }} \stackrel{201}{201}$}

Figure 2. Protein sequence of bovine $\beta$-casein and sequence coverage from the hydrolysate peptides detected. The entire sequence was covered by the 977 peptides identified from the hydrolysate. The known phosphorylation sites are double-underlined with " =". The sequence coverage of the 36 phosphopeptides detected is underlined. five known phosphorylation sites were found. No additional phosphorylation sites were detected. Several representative mass spectra from the phosphopeptides covering the five phosphorylation sites are shown in Figure 3. These spectra are of high quality, allowing unambiguous assignment of the phosphorylation sites. Moreover, for each phosphorylation site, several phosphopeptides containing the phosphorylated amino acid were detected (see Figure 2). The overlapping sequence coverage from these phosphopeptides provides confirmatory information on the phosphorylation site assignment. This example illustrates that the technique of TFA MAAH LC-ESI MS/MS can be used to map the entire protein sequence and identify the modified amino acids in a relatively simple manner for this phosphoprotein.

\section{Characterization of Bovine $\alpha_{S 1}$-Casein Phosphoforms}

Bovine $\alpha_{\mathrm{S} 1}$-casein is another model protein commonly used for phosphoprotein analysis method development. However, this protein is more complex than $\beta$-casein. Bovine $\alpha_{\mathrm{S} 1}$-casein is known to consist of one major and one minor component that have the same amino acid sequence, but differ in their degree of phosphorylation [40]. The major component contains eight phosphate groups $\left(\alpha_{\mathrm{S} 1}\right.$-casein $\left.8 \mathrm{P}\right)$ and the minor component contains one additional phosphorylated serine residue at position $41\left(\alpha_{\mathrm{S} 1}\right.$-casein 9P) (see Figure $4 \mathrm{a}$ for the protein sequence). A recent work using HPLC separation of proteins followed by top-down and bottom-up MS analysis revealed that the bovine $\alpha_{\mathrm{S} 1}$-casein sample purchased from Sigma-Aldrich contained two variants of $\alpha_{\mathrm{S} 1}$-casein, Variant B and Variant C, which differs by one amino acid (Glu-192 for B and Gly-192 for C) [48]. Accurate mass measurement by FT-ICR-MS indicated that Variant $C$ had seven to nine phosphate groups and Variant $B$ had six to nine phosphate groups. Intact protein CID spectra were generated for individual Variant C phosphoforms containing 7 to 9 phosphate groups. Similar to the $\beta$-casein case as discussed above, due to limited backbone breakages (33 fragment ions were assigned in one case), the information from the CID spectra only narrowed down the sequence regions of the phosphorylation sites. The authors applied the bottom-up method on the fractionated protein sample using trypsin digestion [48]. Only two sites from one phosphopeptide CID spectrum could be positively assigned to the protein sequence. This work underscores the challenge of characterizing various isoforms of bovine $\alpha_{\mathrm{S} 1}$-casein.

Contrary to limited report on top-down analysis of bovine $\alpha_{\mathrm{S} 1}$-casein, there were many reports of bottom-up analysis of this protein. For example, with trypsin digestion and phosphopeptide enrichment by IMAC [41] or $\mathrm{TiO}_{2}$ column [42, 43], eight phosphopeptides could be detected, covering nine phosphorylation sites. LC-MALDI MS/MS analysis of tryptic peptides 

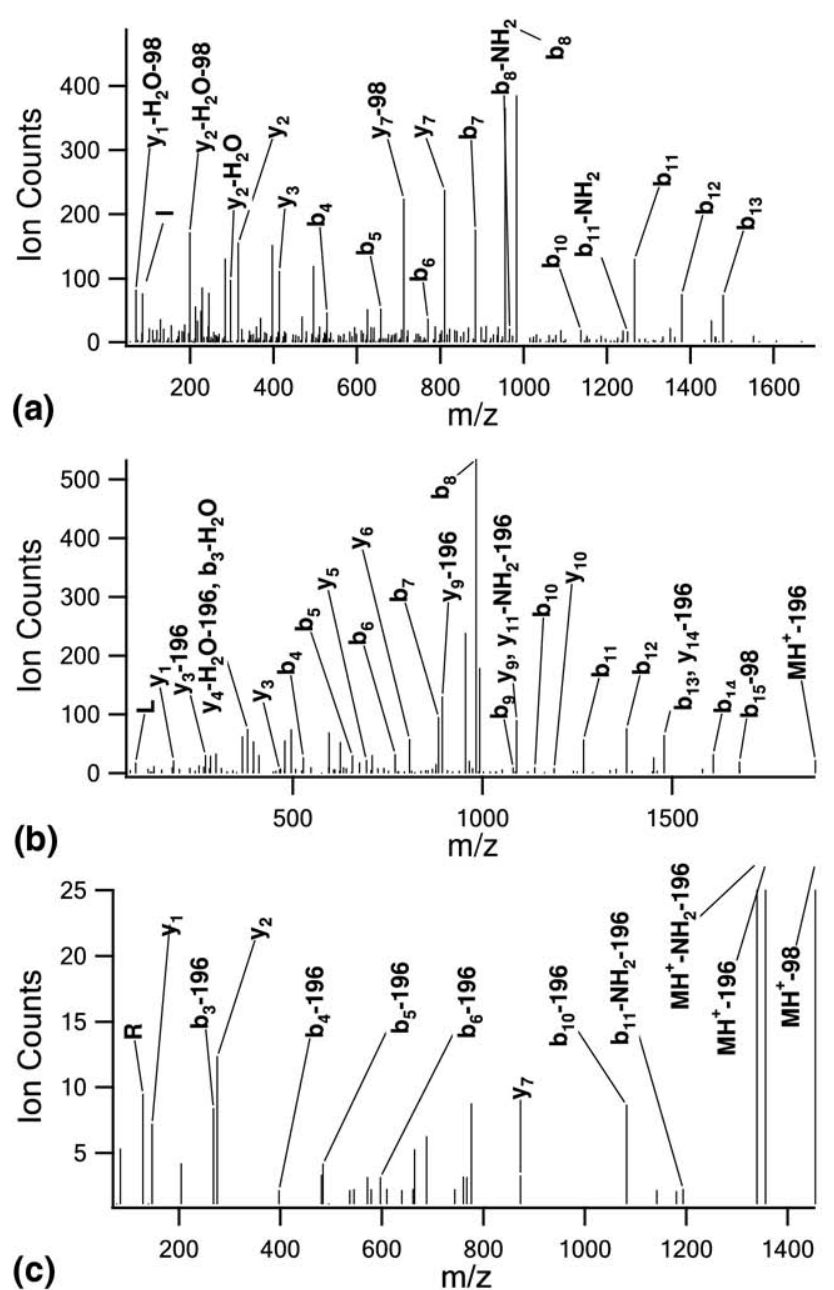

(c)

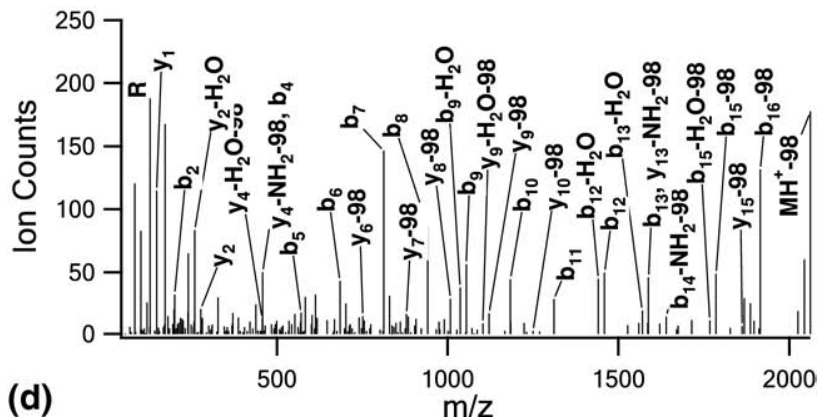

Figure 3. MS/MS spectra of four peptides matched with sequences containing 5 phosphorylation sites in bovine $\beta$-casein. The peptide sequences are (a) RELEELNVPGEIVEpS, (b) RELEELNVPGEIVEpSLpS, (c) pSpSEESITRINKK, and (d) SITRINKKIEKFQpSEEQ.

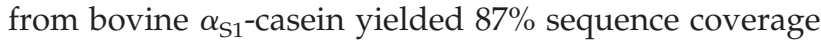
including five phosphopeptides covering nine phosphorylation sites [49]. However, these methods could not identify various phosphoforms of $\alpha_{\mathrm{S} 1}$-casein that are known to exist [40]. We have applied the TFA MAAH LC-ESI MS/MS technique to characterize a bovine $\alpha$-casein sample purchased from Sigma-Aldrich, which was the material supplier for almost all reported MS papers related to bovine $\alpha_{\mathrm{S} 1}$-casein. Detailed char- acterization of this sample should be of significant, not only for the understanding of the structural diversity of bovine $\alpha$-casein, but also for the mass spectrometry researchers who would use this type of sample as a standard for method development.

We first attempted to use direct infusion ESI and then reversed-phase LC-ESI MS on both TOF and FT-ICR instruments to determine the molecular masses of the major components present in the bovine $\alpha$-casein sample. Direct infusion ESI did not provide any useful information on the molecular masses of the protein sample as an unresolved, broad peak was observed, likely due to many adduct ions present in the spectra; phosphates are easy to form adduct ions with many counter ions present in the sample, container and/or capillary tubes. In LC-ESI MS, we could not separate the protein components well and many peaks were observed in the molecular ion region in the mass spectra. However, we could not readily assign these peaks; they were likely from salt and other adduct ions of different forms of caseins. We then used the MALDI TOF/TOF instrument to generate some information on the protein components of the sample. Figure $4 \mathrm{~b}$ shows the MALDI MS spectrum of the bovine $\alpha$-casein sample along with the expanded spectra over the singly and doubly charged molecular ion regions. The mass resolution in the $\mathrm{m} / \mathrm{z}$ region corresponding to the doubly charged molecular ions is sufficient to resolve some of the major components. Knowing the possible phosphoforms and variants that exist for bovine $\alpha_{\mathrm{S} 1}$-casein [40], we can tentatively assign most of the peaks shown in Figure $4 \mathrm{~b}$ based on their molecular masses. The major peak at $\mathrm{m} / \mathrm{z}$ 11,809 is from the doubly charged protonated $\alpha_{\mathrm{S}^{-}}$ casein, Variant $\mathrm{B}$, with eight phosphate groups or $\alpha_{\mathrm{S} 1}$-casein B-8P (the nomenclature is taken from the recommended guidelines [40]) $\left[\mathrm{MH}_{2}^{2+}, \mathrm{M}_{\mathrm{t}} 23,616 \mathrm{Da}\right.$ (theoretical mass) and $\mathrm{M}_{\mathrm{m}} 23,616 \mathrm{Da}$ (measured mass)]. The two peaks at $\mathrm{m} / \mathrm{z} 11,912$ and 11,921 are from the sinapinic acid (SA) adduct ions $\left[\mathrm{MH}_{2}(\mathrm{SA}-18)^{2+}, 23,822\right.$ $\mathrm{Da} ; \mathrm{MH}_{2} \mathrm{SA}^{2+}, 23,840 \mathrm{Da}$. The peak at $m / z 11,849$ can be assigned to the protonated $\alpha_{\mathrm{S} 1}$-casein, Variant $\mathrm{B}$, with nine phosphate groups or $\alpha_{\mathrm{S} 1}$-casein $\mathrm{B}-9 \mathrm{P}\left(\mathrm{MH}_{2}^{2+}\right.$, $23,696 \mathrm{Da}$ ). Another peak at $\mathrm{m} / \mathrm{z} 11,772$ is most likely from the overlap signals of protonated $\alpha_{\mathrm{S} 1}$-casein, Variant $\mathrm{B}$, with seven phosphate groups or $\alpha_{\mathrm{S} 1}$-casein B-7P $\left(\mathrm{MH}_{2}^{2+}, 23,536 \mathrm{Da}\right)$ and protonated $\alpha_{\mathrm{S} 1}$-casein, Variant $\mathrm{C}$, with eight phosphate groups or $\alpha_{\mathrm{S} 1}$-casein $\mathrm{C}-8 \mathrm{P}$ $\left(\mathrm{MH}_{2}^{2+}, 23,544 \mathrm{Da}\right)$. Other unassigned peaks may be from impurities (the sample contained $>70 \% \alpha$-casein according to the supplier) and salt/matrix adduct ions of proteins.

The above MALDI MS results indicated that the $\alpha$-casein sample might contain $\alpha_{\mathrm{S} 1}$-casein, Variant $\mathrm{B}$, with seven, eight, and nine phosphate groups and possibly Variant $C$ with eight phosphate groups. Likely other phosphoforms of Variant C (e.g., those containing seven or nine phosphate groups) were present in the sample, but their peaks were not resolved in MALDI MS. As shown below, this sample also contained a small 


\section{Bovine $\alpha_{\mathrm{s} 1}$-casein, variant $\mathrm{B}$}

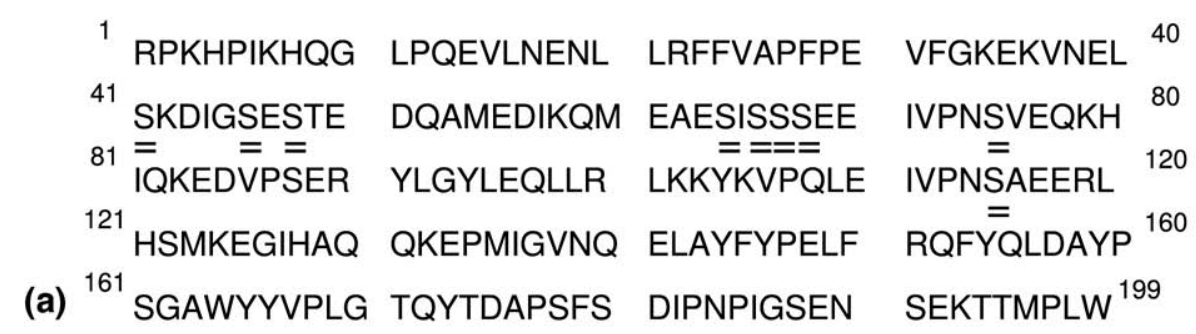

(b)

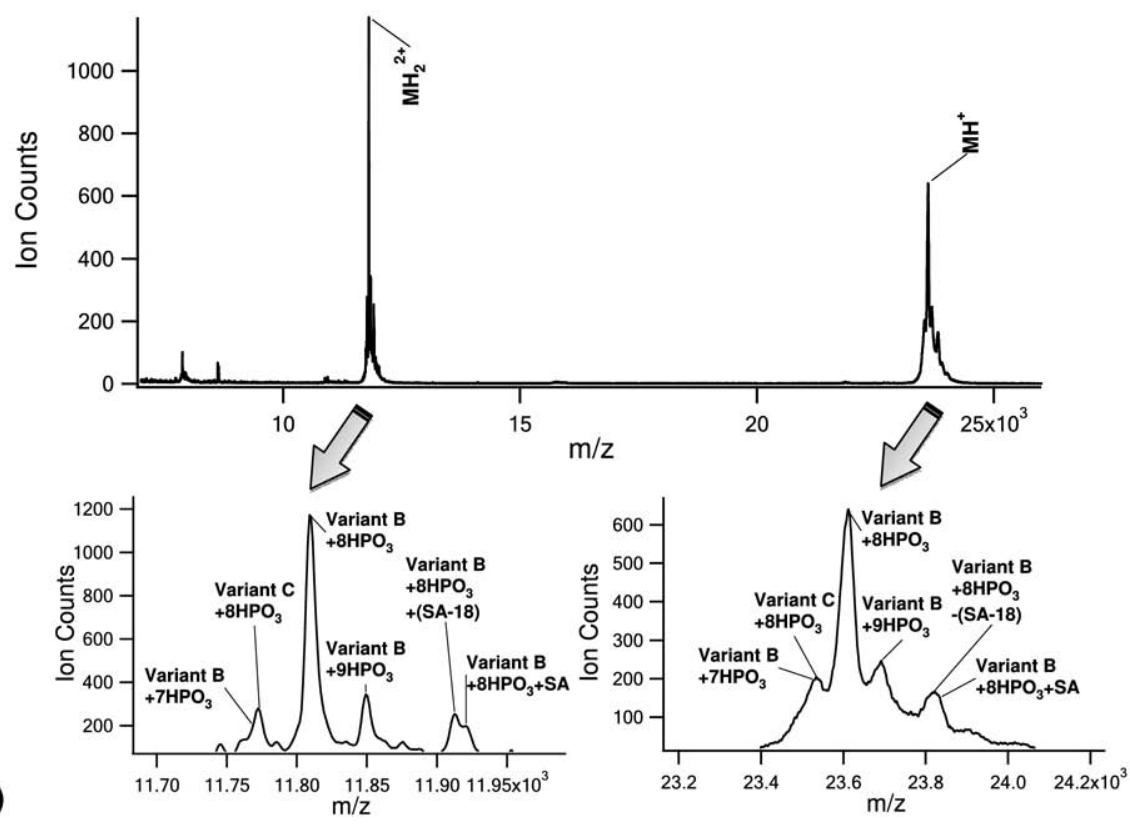

Figure 4. (a) Protein sequence of bovine $\alpha_{\mathrm{S} 1}$-casein, Variant B, with the phosphorylation sites double-underlined with " =". (b) MALDI-TOF mass spectrum of the $\alpha$-casein sample analyzed along with the expanded spectra covering the singly and doubly charged molecular ion regions.

amount of $\alpha_{\mathrm{S} 2}$-casein. However, the spectra shown in Figure $4 \mathrm{~b}$ do not show any peaks corresponding to the possible phosphoforms of $\alpha_{\mathrm{S} 2}$-casein in the mass range between 25,000 and 25,500 Da. The signals of these proteins were likely suppressed by the dominant species, $\alpha_{\mathrm{S} 1}$-casein. We note that it has been shown that complete separation of various casein isoforms was not possible using a HPLC system even equipped with a long, 70-cm C5 column [48]. Thus, even if a more effective HPLC fractionation method were applied to the sample, one would still end up with a mixture, albeit with reduced complexity. So the question is how to map the phosphorylation sites from a sample containing a mixture of phosphoforms and/or protein variants. Our strategy is to generate two peptide sequence maps, one from the hydrolysate of the $\alpha$-casein sample and another one from the IMAC enriched peptides from the hydrolysate, and then compare the two maps to generate information on the phosphorylation sites and possibly assign them to individual phosphoforms (i.e., those containing seven to nine phosphate groups).

In the analysis of the $\alpha$-casein hydrolysate using LC-ESI MS/MS, a total of 3262 MS/MS spectra were collected in a single run. These spectra matched with 1455 peptides (911 unique ones) from $\alpha_{\mathrm{S} 1}$-casein B (see Supplemental Table S3). Except one amino acid, $\mathrm{S}^{48}$, all other amino acids are covered by these peptides with much redundant sequence coverage from overlapping peptide sequences. When the protein sequence in the MASCOT search was changed to $\alpha_{\mathrm{S} 1}$-casein $\mathrm{C}, 131$ peptides (52 unique ones) were matched to the variant site (i.e., all these peptides contained Gly-192, instead of Glu-192) (see Supplemental Table S4A). In the case of Variant $B, 21$ peptides (12 unique ones) were matched to the variant site, i.e., the peptides containing Glu-192 (see Supplemental Table S4B). There are more peptides matched with Variant B than Variant C, which is likely due to the difference in protein concentration. This notion is consistent with the MALDI MS result which showed much higher signals from Variant B than Variant $\mathrm{C}$. Since only one amino acid close to the C-terminus is altered in a protein containing 273 amino acids, it is reasonable to assume that the ionization efficiency for Variant $B$ is very similar to that of Variant C. Based on the MALDI signal intensities of Variant B-8P and Variant C-8P (assuming equal contribution from Variant 
C-8P and Variant B-7P to the overlap peak around $\mathrm{m} / \mathrm{z}$ $11,172)$, it can be estimated that the concentration of Variant C in the sample was less than $10 \%$ of Variant B. Because near complete sequence coverage of $\alpha$-casein was obtained, the hydrolysate MS/MS spectra were searched again using the sequences of other known variants (i.e., Variant A, D-H) [40]. None of these variants could be found. Thus, it can be concluded that the $\alpha$-casein sample was composed of a major component, Variant B, and a minor component, Variant C.

Among the 911 unique peptides matched with $\alpha_{\mathrm{S}^{-}}$ casein B, there are 165 phosphopeptides (18\%). These are mainly singly or doubly phosphorylated peptides that can be used to assign eight phosphorylation sites in $\alpha_{\mathrm{S} 1}$-casein. To increase the detectability of phosphopeptides, particularly those containing multiple phosphate groups, IMAC with $\mathrm{Fe}^{3+}$-immobilized beads was used to enrich the phosphopeptides from the hydrolysate. LC-ESI MS/MS analysis of the enriched sample generated 4023 MS/MS spectra, resulting in 1171 peptides (588 unique ones) matched to $\alpha_{\mathrm{S} 1}$-casein B (see Supplemental Table S5). From these many phosphopeptide matches, we can readily locate the phosphorylation sites in the $\alpha$-casein sequence. Combined with the peptide sequence map generated from the un-enriched hydrolysate, we can also pinpoint which $\mathrm{S}, \mathrm{T}$, or $\mathrm{Y}$ is not phosphorylated with high confidence.

Figure 5 shows the MS/MS spectra of several peptides along with sequence assignments that cover nine phosphorylation sites $\left(S^{41}, S^{46}, S^{48}, S^{64}, S^{66}, S^{67}, S^{68}, S^{75}\right.$, and $\mathrm{S}^{115}$ ). These phosphorylation sites have been reported previously [40]. No spectral evidence supports the presence of a phosphate group in other $\mathrm{S}, \mathrm{T}$, or $\mathrm{Y}$. There was one report from the top-down method suggesting that $Y^{144}$ and $Y^{146}$ could be phosphorylated for $\alpha_{\mathrm{S} 1}$-casein [48]. Our data did not indicate any phosphorylation on these two Y residues. Apparently the $\alpha_{\mathrm{S} 1^{-}}$ casein phosphoform containing nine phosphate groups in this particular sample exists as only one form.

The phosphoform containing eight phosphate groups should be the major component in the bovine $\alpha$-casein sample. Among the nine phosphorylation sites indicated above, $\mathrm{S}^{41}$ is positively identified as a site that can exist as a nonphosphorylated serine. Figure 6a shows the MS/MS spectrum of a peptide containing $\mathrm{S}^{41}$, $\mathrm{S}^{46}$, and $\mathrm{S}^{48}$ along with the peak assignment, illustrating that $S^{41}$ is not phosphorylated. Many matched peptides contain $\mathrm{S}^{46}$ and $\mathrm{S}^{48}$ and all suggest that these two sites are phosphorylated. There are 23 spectral matches to peptide sequences containing ${ }^{59}$ MEAESIS ${ }^{66}$ including 6 unique peptides. These spectra indicate that these two sites are always phosphorylated. On $S^{68}$ and $S^{75}$, we examined the spectral matches to peptide sequences containing ${ }^{68}$ SEEIVPNS ${ }^{75}$ with $S^{68}$ as the fixed $\mathrm{N}$-terminus (i.e., the C-terminal peptide ladders can be expanded beyond $\mathrm{S}^{75}$ ). There are 88 spectral matches including 29 unique peptides, and all of them indicate that $S^{68}$ and $\mathrm{S}^{75}$ are phosphorylated. Similarly, we examined the spectral matches to peptide sequences containing $S^{75}$
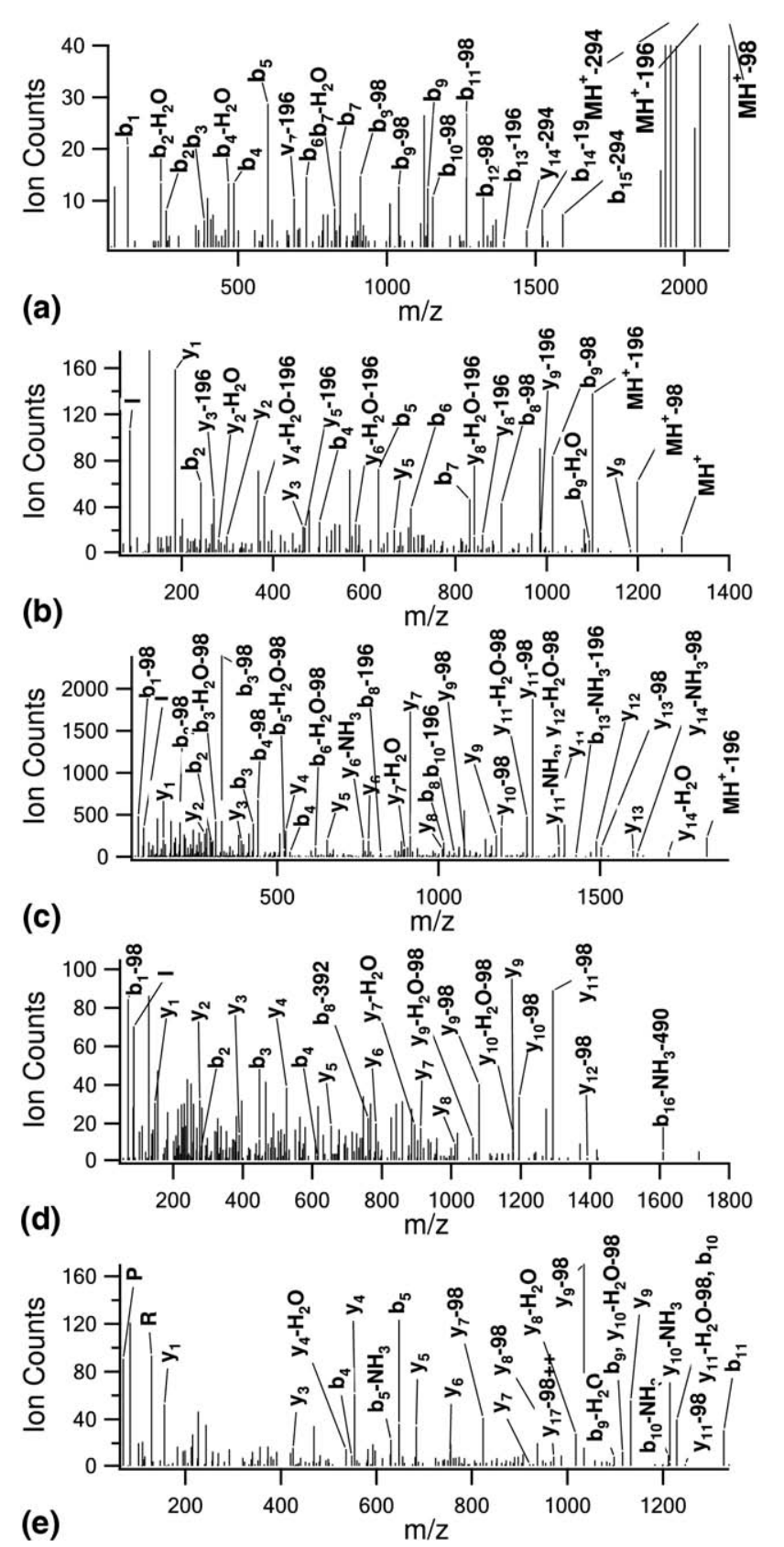

Figure 5. MS/MS spectra of five peptides matched with sequences

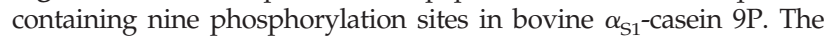
peptide sequences are (a) KEKVNELPSKDIGPSEpSTED, (b) IKDMEAEpSIpS, (c) pSEEIVPNPSVEQKHIQK, (d) pSIpSpSpSEEIVPNPSVEQKHIQK, and (e) KKYKVPQLEIVPNPSAEERLH.

alone or $\mathrm{S}^{105}$ alone and found that these two sites were always phosphorylated. However, $\mathrm{S}^{67}$ can exist as a nonphosphorylated serine (see examples of MS/MS spectra shown in Figure 6b, c). Strong evidence comes from the inspection of the spectral matches to peptide sequences containing ${ }^{67}$ SSEEIVPNS ${ }^{75}$ with $\mathrm{S}^{67}$ as the fixed $\mathrm{N}$ terminus (Figure $6 \mathrm{~b}$ ). There are 78 spectra (28 unique peptides) and 10 spectra (six unique peptides) matched with peptide sequences containing three phosphorylated serine and two phosphorylated serine, respec- 

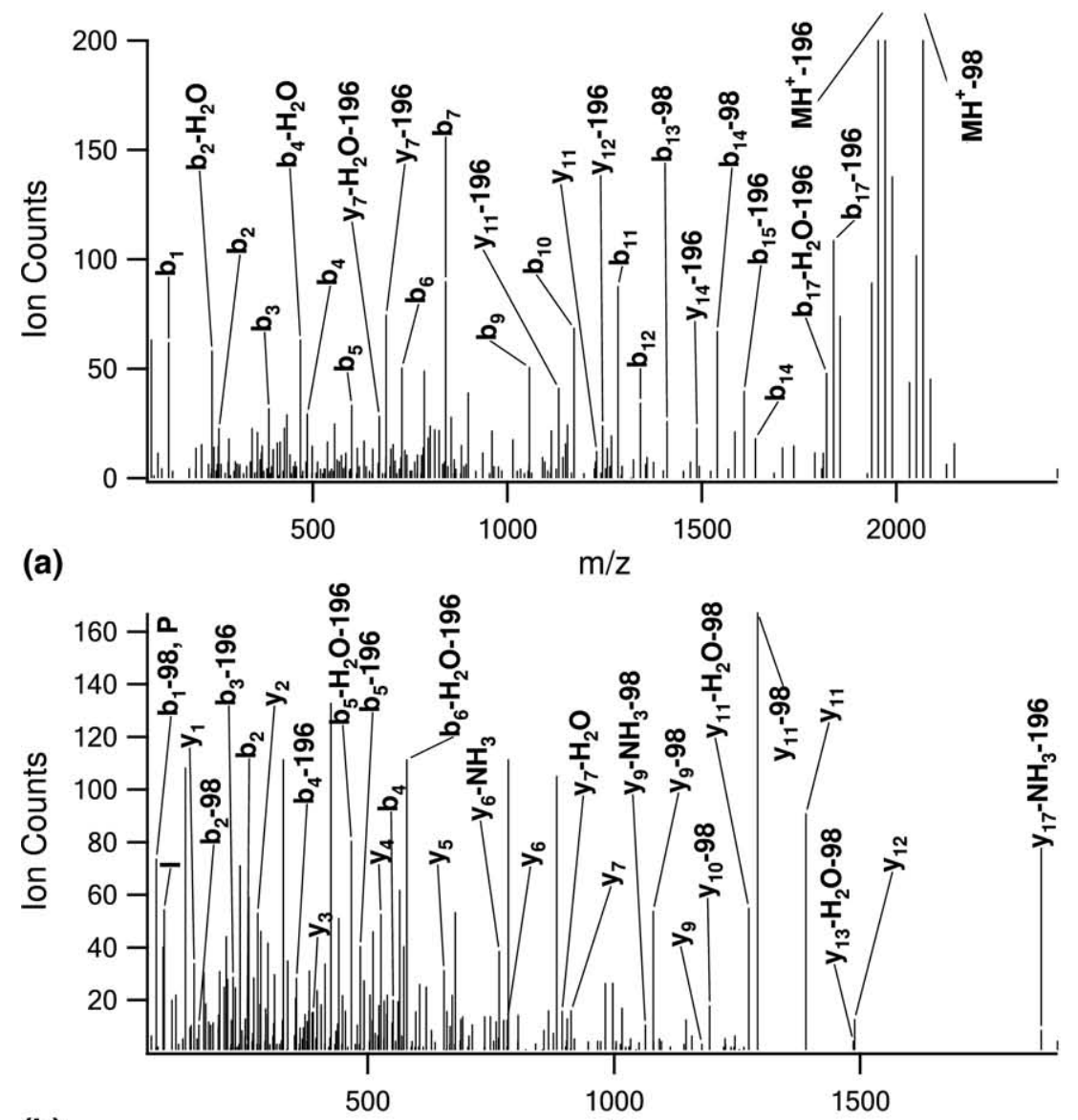

(b)
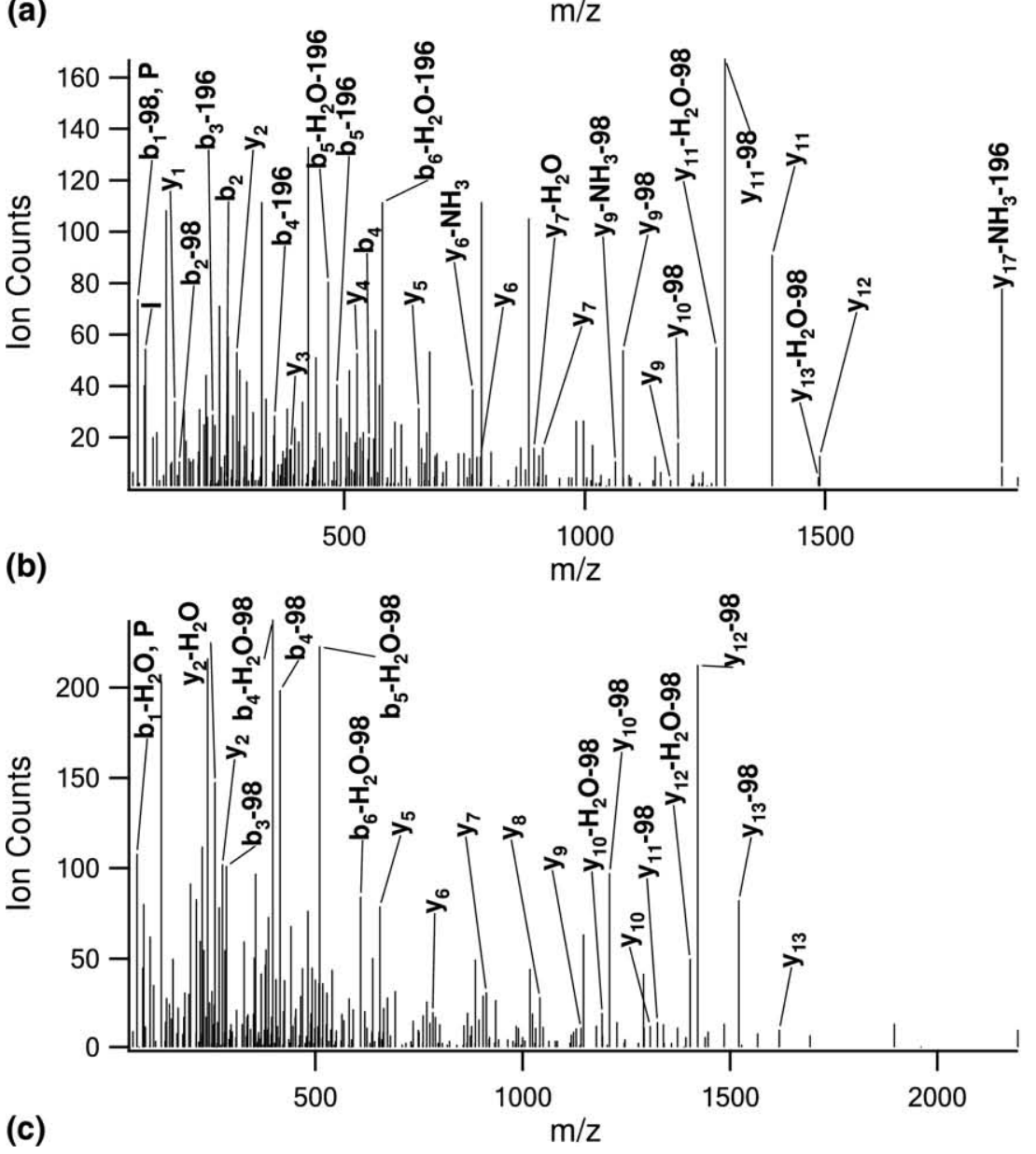

Figure 6. (a) MS/MS spectrum of a representative peptide revealing that $\mathrm{S}^{41}$ in $\alpha_{\mathrm{S} 1}$-casein can exist as a nonphosphorylated serine. The peptide sequences are (a) KEKVNELSKDIGpSEpSTED, (b) SpSEEIVPNPSVEQKHIQKE, and (b) pSSpSEEIVPNpSVEQKHIQK. The fragment ion information shown in the spectra do not allow unambiguous assignment of the un-modified serine. However, other MS/MS data indicate that $S^{64}, S^{66}$, and $S^{68}$ are always phosphorylated, leading to the identification of $S^{67}$ as the sole nonphosphorylated serine (see Text).

tively. MASCOT search engine assigned the nonphosphorylated serine as either $S^{67}$ or $S^{68}$ for the top two ranked matches with almost the same scores. Apparently, the MS/MS spectra could not positively differentiate the two matches. Manual interpretation of the matched spectra also failed to pinpoint which serine was not phosphorylated. This difficulty has been noted by others where a similar situation was encountered in dealing with a cluster of serine in a short sequence region of human $\alpha$-casein [50]. However, since $S^{68}$ is always phosphorylated as indicated earlier, only $\mathrm{S}^{67}$ in these sequences should be nonphosphorylated. It is 
interesting to note that the occurrence rate for nonphosphorylated $S^{67}$ is low $(10 / 88$ or $11 \%)$, compared with the presence of phosphorylated $S^{68}$ in matched peptide sequences $(78 / 88$ or $89 \%)$.

There are 23 matches to peptide sequences containing ${ }^{64}$ SISSS ${ }^{68}$ and, among them, five matches have all four serine phosphorylated, while 18 matches have three serine phosphorylated. Similarly, among the 52 matches containing the sequence of ${ }^{6} \mathrm{SSSEE}^{70}, 28$ matches have three serine phosphorylated and 24 matches have two serine phosphorylated in their sequences. MASCOT search engine again could not pinpoint which $S$ was not phosphorylated. Manual inspection of the MS/MS spectra also failed to locate the exact position of the nonphosphorylated serine. However, as discussed earlier, by examining the spectral matches from sequences containing $S^{64}$ and $S^{66}$ as well as sequences containing $S^{68}$ and $S^{75}$, we are able to determine that only $S^{67}$ can exist as the nonphosphorylated residue among the cluster of serine from $S^{64}$ to $S^{115}$. Thus, we can conclude that there are two possible phosphoforms containing eight phosphate groups, i.e., the nine phosphorylation sites shown in $\alpha_{\mathrm{S} 1}$-casein 9P minus either $S^{41}$ or $S^{67}$. Among the two, minus $S^{41}$ appears to be the major phosphoform. This is inferred from the comparison of the numbers of sequences matched with the phosphopeptides containing $S^{41}$ or $S^{67}$. For $S^{41}$, there are 323 matched phosphopeptides (including the redundant matches) containing the sequence of ${ }^{41}$ SKDIGSES $^{48}$. Only 29 of them (9\%) have all three serine phosphorylated and the rest are doubly phosphorylated at $S^{46}$ and $S^{68}$. The high occurrence rate of nonphosphorylated $S^{41}$ $(89 \%)$, compared with that of $S^{67}(11 \%)$, should suggest that the minus $S^{41}$ phosphoform have higher concentration than the minus $S^{67}$ phosphoform. This is consistent with the common notion that the major form of bovine $\alpha$-casein containing eight phosphate groups is the one having phosphorylation sites at $S^{46}, S^{48}, S^{64}, S^{66}, S^{67}, S^{68}$, $S^{75}$, and $S^{115}[40]$.

For the phosphoform containing seven phosphate groups, our data did not provide any evidence on the concurrent presence of two nonphosphorylated residues among $S^{64}, S^{66}$, and $S^{67}$. No MS/MS spectra matched with sequences containing both unmodified $S^{64}$ and $S^{66}$ or unmodified $S^{64}$ and $S^{67}$, or unmodified $S^{66}$ and $S^{67}$. The only possibility of minus two phosphorylated sites from the nine sites is from minus $S^{41}$ and $S^{67}$. Thus, there is only one possible phosphoform with seven phosphate groups having phosphorylation sites at $S^{46}, S^{48}, S^{64}, S^{66}, S^{68}, S^{75}$, and $S^{115}$.

The above discussion illustrates that the TFA MAAH method combined with LC-ESI MS/MS can be used to assign the possible phosphorylation sites from various phosphoforms of $\alpha_{\mathrm{S} 1}$-casein containing seven to nine phosphate groups and determine the presence of two variants, $\mathrm{B}$ and $\mathrm{C}$ in the bovine $\alpha$-casein sample. To our knowledge, such detailed phosphorylation site assignments for bovine $\alpha_{\mathrm{S} 1}$-casein have never been reported. For future work, high-resolution protein separation is needed to purify individual phosphoforms and/or variants so that phosphorylation sites can be unambiguously assigned to a specific phosphoform [51]. A case in point is related to the characterization of the other minor component in the sample, $\alpha_{\mathrm{S} 2}$-casein. Searching the MS/MS spectra obtained from one single LC-MS run of the hydrolysate against $\alpha_{\mathrm{S} 2}$-casein resulted in 118 sequence matches including 62 unique peptides (see Supplemental Table S6A). To detect more peptides, two additional LC-MS runs (replicates) using the precursor ion exclusion (PIE) strategy [30] were carried out. Database search of the merged data from all three runs resulted in the identification of 264 peptides (135 unique peptides; see Supplemental Table S6B). Supplemental Figure $\mathrm{S} 4$ shows the protein sequence coverage of $\alpha_{\mathrm{S} 2}$-casein by these peptides (79\%). Using the MS/MS spectra obtained from the IMAC-enriched sample, we found 313 sequence matches, including 212 unique phosphopeptides (see Supplemental Table S7). From these data, eight out of 12 known phosphorylation sites can be determined (see Supplemental Figure S4 for site assignments). Clearly, because of the low concentration of $\alpha_{\mathrm{S} 2}$-casein present in the sample, both sequence and phosphorylation site coverages are lower than those for $\alpha_{\mathrm{S} 1}$-casein. Fractionation of $\alpha_{\mathrm{S} 2}$-casein from the sample should improve the characterization of $\alpha_{\mathrm{S} 2}$-casein.

\section{Conclusions}

We have developed a new set-up for microwaveassisted acid hydrolysis that generates reproducible hydrolysates using a simple domestic microwave oven. We have combined this method with one dimensional LC-ESI QTOF tandem MS for mapping protein sequences and modifications. Near complete sequence coverage can be obtained for proteins with molecular masses of up to 67000 Da (i.e., BSA). For BSA, only about $1 \mu \mathrm{g}$ of hydrolysate was required to generate greater than $97 \%$ sequence coverage. Protein modifications, including phosphorylation, can be characterized. In the case of bovine $\beta$-casein, the entire sequence was mapped, including information on five phosphorylation sites. For a bovine $\alpha$-casein sample, MALDI MS analysis of the intact proteins indicated that it was a mixture containing at least three different phosphoforms with 7 to 9 phosphate groups plus two protein variants, B and C. To characterize the phosphoforms, a strategy based on the generation of two comprehensive peptide maps, one from the hydrolysate and another one from the IMAC-enriched peptides, was developed. The two sequence maps covered the entire protein sequence and many MS/MS spectra matched with the phosphopeptides. It was shown that, in the sample analyzed, bovine $\alpha_{\mathrm{S} 1}$-casein phosphoform containing 9 phosphate groups existed in one form and their phosphorylation sites were assigned to $S^{41}, S^{46}, S^{48}, S^{64}, S^{66}$, $S^{67}, S^{68}, S^{75}$ and $S^{115}$. The phosphoform containing eight phosphate groups existed in two possible forms with the major one having phosphorylation sites at $S^{46}, S^{48}$, 
$\mathrm{S}^{64}, \mathrm{~S}^{66}, \mathrm{~S}^{67}, \mathrm{~S}^{68}, \mathrm{~S}^{75}$ and $\mathrm{S}^{115}$, and the minor one having phosphorylation sites at $S^{41}, S^{46}, S^{48}, S^{64}, S^{66}, S^{68}, S^{75}$ and $\mathrm{S}^{115}$. The phosphoform containing 7 phosphate groups existed in only one possible form with phosphorylation sites at $S^{46}, S^{48}, S^{64}, S^{66}, S^{68}, S^{75}$ and $S^{115}$.

It should be noted that many other modifications, such as methylation, acetylation, oxidation, etc., do not affect the peptide detectability significantly and their modifications would be retained on amino acids after hydrolysis, therefore, we expect that these modifications can be identified from the direct analysis of the hydrolysate by LC-ESI MS/MS. However, glycosylation sites in a glycoprotein cannot be characterized by the technique because glycans would be hydrolyzed from the amino acid side chains, resulting in peptides indistinguishable from the unmodified peptides. It is interesting to note that MAAH has been reported to be useful to generate oligosaccharide ladders for mass spectrometric sequencing [52-54].

In addition to the use of this method to generate reproducible sequence information on a purified protein or a simple mixture, this MAAH method should also be applicable for generating hydrolysates from more complex mixtures in shotgun proteomics. The performance and applications of this method for shotgun proteomics will be reported in future publications.

\section{Acknowledgments}

The authors acknowledge funding for this work by the Natural Sciences and Engineering Research Council of Canada, the Canada Research Chairs program, the PrioNet Canada and the Alberta Prion Research Institute.

\section{Appendix A Supplementary Material}

Supplementary material associated with this article may be found in the online version at doi:10.1016/ j.jasms.2010.04.014.

\section{References}

1. Chait, B. T. Mass Spectrometry: Bottom-Up or Top-Down? Science 2006, 314, 65-66.

2. Hoffman, M. D.; Sniatynski, M. J.; Kast, J. Current Approaches for Global Post-Translational Modification Discovery and Mass Spectrometric Analysis. Anal. Chim. Acta 2008, 627, 50-61.

3. McLafferty, F. W.; Breuker, K.; Jin, M.; Han, X. M.; Infusini, G.; Jiang, H.; Kong, X. L.; Begley, T. P. Top-Down, MS , a Powerful Complement to the High Capabilities of Proteolysis Proteomics. FEBS J. 2007, 274, 6256-6268.

4. Running, W. E.; Ravipaty, S.; Karty, J. A.; Reilly, J. P. A Top-Down/ Bottom-up Study of the Ribosomal Proteins of Caulobacter crescentus. J. Proteome Res. 2007, 6, 337-347.

5. Sharma, S.; Simpson, D. C.; Tolic, N.; Jaitly, N.; Mayampurath, A. M.; Smith, R. D.; Pasa-Tolic, L. Proteomic Profiling of Intact Proteins Using Wax-RPLC 2-D Separations and FTICR Mass Spectrometry. J. Proteome Res. 2007, 6, 602-610.

6. Borchers, C. H.; Thapar, R.; Petrotchenko, E. V.; Torres, M. P.; Speir, J. P.; Easterling, M.; Dominski, Z.; Marzluff, W. F. Combined Top-Down and Bottom-up Identifies a Phosphorylation Protein That Contributes to Proteomics Site in Stem-Loop-Binding High-Affinity RNA Binding. Proc. Natl. Acad. Sci. U.S.A. 2006, 103, 3094-3099.

7. Ji, C. J.; Wang, Z. P.; Li, L. Protein Mass Measurement Combined with Mass Spectrometric Sequencing of Protein Digests for Detection and Characterization of Protein Modifications. Can. J. Chem. [Revue Canadienne de Chimie] 2006, 84, 986-997.
8. Millea, K. M.; Krull, I. S.; Cohen, S. A.; Gebler, J. C.; Berger, S. J. Integration of Multidimensional Chromatographic Protein Separations with a Combined "Top-Down" and "Bottom-Up" Proteomic Strategy. J. Proteome Res. 2006, 5, 135-146.

9. Kelleher, N. L.; Lin, H. Y.; Valaskovic, G. A.; Aaserud, D. J.; Fridriksson, E. K.; McLafferty, F. W. Top-Down versus Bottom-Up Protein Characterization by Tandem High-Resolution Mass Spectrometry. J. Am. Chem. Soc. 1999, 121, 806-812.

10. Zubarev, R. A. Electron-Capture Dissociation. Tandem Mass Spectrometry. Curr. Opin. Biotechnol. 2004, 15, 12-16.

11. Liu, J.; Huang, T. Y.; McLuckey, S. A. Top-Down Protein Identification/ Characterization of a Priori Unknown Proteins Via Ion Trap CollisionInduced Dissociation and Ion/Ion Reactions in a Quadrupole/Time-ofFlight Tandem Mass Spectrometer. Anal. Chem. 2009, 81, 1433-1441.

12. Breuker, K.; Jin, M.; Han, X. M.; Jiang, H. H.; McLafferty, F. W. Top-Down Identification and Characterization of Biomolecules by Mass Spectrometry. J. Am. Soc. Mass Spectrom. 2008, 19, 1045-1053.

13. Zhong, H. Y.; Zhang, Y.; Wen, Z. H.; Li, L. Protein Sequencing by Mass Analysis of Polypeptide Ladders after Controlled Protein Hydrolysis. Nat. Biotechnol. 2004, 22, 1291-1296.

14. Zhong, H. Y.; Marcus, S. L.; Li, L. Microwave-Assisted Acid Hydrolysis of Proteins Combined with Liquid Chromatography MALDI MS/MS for Protein Identification. J. Am. Soc. Mass Spectrom. 2005, 16, 471-481.

15. Lill, J. R.; Ingle, E. S.; Liu, P. S.; Pham, V.; Sandoval, W. N. MicrowaveAssisted Proteomics. Mass Spectrom. Rev. 2007, 26, 657-671.

16. Sandoval, W. N.; Pharn, V. C.; Lill, J. R. Recent Developments in Microwave-Assisted Protein Chemistries-Can This Be Integrated into the Drug Discovery and Validation Process? Drug Discov. Today 2008, 13, 1075-1081.

17. Pramanik, B. N.; Mirza, U. A.; Ing, Y. H.; Liu, Y. H.; Bartner, P. L.; Weber, P. C.; Bose, M. K. Microwave-Enhanced Enzyme Reaction for Protein Mapping by Mass Spectrometry: A New Approach to Protein Digestion in Minutes. Protein Sci. 2002, 11, 2676-2687.

18. Sandoval, W. N.; Pham, V.; Ingle, E. S.; Liu, P. S.; Lill, J. R. Applications of Microwave-Assisted Proteomics in Biotechnology. Combinat. Chem. High Throughput Screening. 2007, 10, 751-765.

19. Swatkoski, S.; Russell, S. C.; Edwards, N.; Fenselau, C. Rapid Chemical Digestion of Small Acid-Soluble Spore Proteins for Analysis of Bacillus Spores. Anal. Chem. 2006, 78, 181-188.

20. Sze, S. K.; Wang, W.; Meng, W: Yuan, R. D.; Guo, T. N.; Zhu, Y.; Tam J. P. Elucidating the Structure of Cyclotides by Partial Acid Hydrolysis and LC-MS/MS Analysis. Anal. Chem. 2009, 81, 1079-1088.

21. Wang, N.; MacKenzie, L.; De Souza, A. G.; Zhong, H. Y.; Goss, G.; Li, L. Proteome Profile of Cytosolic Component of Zebrafish Liver Generated by LC-ESI MS/MS Combined with Trypsin Digestion and MicrowaveAssisted Acid Hydrolysis. J. Proteome Res. 2007, 6, 263-272.

22. Yassine, M. M.; Guo, N.; Zhong, H.; Li, L.; Lucy, C. A. Off-Line Coupling of Preparative Capillary Zone Electrophoresis with Microwave-Assisted Acid Hydrolysis and Matrix-Assisted Laser Desorption Ionization Mass Spectrometry for Protein Sequencing. Anal. Chim. Acta 2007, 597, 41-49.

23. Lin, S.; Yun, D.; Qi, D. W.; Deng, C. H.; Li, Y.; Zhang, X. M. Novel Microwave-Assisted Digestion by Trypsin-Immobilized Magnetic Nanoparticles for Proteomic Analysis. J. Proteome Res. 2008, 7, 12971307.

24. Swatkoski, S.; Gutierrez, P.; Wynne, C.; Petrov, A.; Dinman, J. D.; Edwards, N.; Fenselau, C. Evaluation of Microwave-Accelerated Residue-Specific Acid Cleavage for Proteomic Applications. J. Proteome Res. 2008, 7, 579-586.

25. Chen, W. Y.; Chen, Y. C. Acceleration of Microwave-Assisted Enzymatic Digestion Reactions by Magnetic Beads. Anal. Chem. 2007, 79, 2394-2401.

26. Juan, H. F.; Chang, S. C.; Huang, H. C.; Chen, S. T. A New Application of Microwave Technology to Proteomics. Proteomics 2005, 5, 840-842.

27. Hauser, N. J.; Han, H. L.; McLuckey, S. A.; Basile, F. Electron Transfer Dissociation of Peptides Generated by Microwave D-Cleavage Digestion of Proteins. J. Proteome Res. 2008, 7, 1867-1872.

28. Wu, X. P.; Cheng, Y. S.; Liu, J. Y. Microwave-Enhanced Ink Staining for Fast and Sensitive Protein Quantification in Proteomic Studies. J. Proteome Res. 2007, 6, 387-391.

29. Nair, S. S.; Romanuka, J.; Billeter, M.; Skjeldal, L.; Emmett, M. R. Nilsson, C. L.; Marshall, A. G. Structural Characterization of an Unusually Stable Cyclic Peptide, Kalata B2 from Oldenlandia affinis. Biochim. Biophys. Acta (BBA) Prot. Proteom. 2006, 1764, 1568-1576.

30. Wang, N.; Li, L. Exploring the Precursor Ion Exclusion Feature of Liquid Chromatography-Electrospray Ionization Quadrupole Time-of-Flight Mass Spectrometry for Improving Protein Identification in Shotgun Proteome Analysis. Anal. Chem. 2008, 80, 4696-4710.

31. Giberson, R. T.; Demaree, R. S. Microwave Fixation-Understanding the Variables to Achieve Rapid Reproducible Results. Microscop. Res. Tech. 1995, 32, 246-254.

32. Kok, L. P.; Boon, M. E.; Smid, H. M. The Problem of Hot-Spots in Microwave Equipment Used for Preparatory Techniques-Theory and Practice. Scanning 1993, 15, 100-109.

33. Polshettiwar, V.; Varma, R. S. Microwave-Assisted Organic Synthesis and Transformations Using Benign Reaction Media. Acc. Chem. Res. 2008, 41, 629-639.

34. Dallinger, D.; Kappe, C. O. Microwave-Assisted Synthesis in Water as Solvent. Chem. Rev. 2007, 107, 2563-2591. 
35. de la Hoz, A.; Diaz-Ortiz, A.; Moreno, A. Microwaves in Organic Synthesis. Thermal and Nonthermal Microwave Effects. Chem. Soc. Rev. 2005, 34, 164-178.

36. Damm, M.; Kappe, C. O. Parallel Microwave. Chemistry in Silicon Carbide Reactor Platforms: An In-Depth Investigation into Heating Characteristics. Mol. Divers 2009, 13, 529-543.

37. Gebremedhin, M.; Zhong, H. Y. Wang, S. H.; Weinfeld, M.; Li, L. Benefit of Microwave-Assisted Acid Hydrolysis of Proteins for Mass Spectrometric Profiling of the Human Heart Tissue Proteome. Rapid Commun. Mass Spectrom. 2007, 21, 2779-2783.

38. Richter, R. C.; Link, D.; Kingston, H. M. Microwave-Enhanced Chemistry. Anal. Chem. 2001, 73, 30A-37A.

39. Brown, J. R. Structure of Bovine Serum-Albumin. Fed. Proc. 1975, 34 591-591.

40. Farrell, H. M.; Jimenez-Flores, R.; Bleck, G. T.; Brown, E. M.; Butler, J. E.; Creamer, L. K.; Hicks, C. L.; Hollar, C. M.; Ng-Kwai-Hang, K. F. Swaisgood, H. E. Nomenclature of the Proteins of Cows' Milk-Sixth Revision. J. Dairy Sci. 2004, 87, 1641-1674.

41. Stensballe, A.; Jensen, O. N. Phosphoric Acid Enhances the Performance of Fe(II) Affinity Chromatography and Matrix-Assisted Laser Desorption/Ionization Tandem Mass Spectrometry for Recovery, Detection, and Sequencing of Phosphopeptides. Rapid Commun. Mass Spectrom. 2004, 18, 1721-1730.

42. Larsen, M. R.; Thingholm, T. E.; Jensen, O. N.; Roepstorff, P.; Jorgensen, T. J. D. Highly Selective Enrichment of Phosphorylated Peptides from Peptide Mixtures Using Titanium Dioxide Microcolumns. Mol. Cell. Proteom. 2005, 4, 873-886.

43. Imanishi, S. Y.; Kochin, V.; Ferraris, S. E.; de Thonel, A.; Pallari, H. M.; Corthals, G. L.; Eriksson, J. E. Reference-Facilitated PhosphoproteomicsFast and Reliable Phosphopeptide Validation by MicroLC-ESI-Q-TOF MS/MS. Mol. Cell. Proteom. 2007, 6, 1380-1391.

44. Kweon, H. K.; Hakansson, K. Selective Zirconium Dioxide-Based Enrichment of Phosphorylated Peptides for Mass Spectrometric Analysis. Anal. Chem. 2006, 78, 1743-1749.

45. Wu, S. L.; Kim, J.; Hancock, W. S.; Karger, B. Extended Range Proteomic Analysis (ERPA): A New and Sensitive LC-MS Platform for High
Sequence Coverage of Complex Proteins with Extensive PostTranslational Modifications-Comprehensive Analysis of $\beta$-Casein and Epidermal Growth Factor Receptor (EGFR). J. Proteome Res. 2005, 4 $1155-1170$

46. Shi, S. D. H.; Hemling, M. E.; Carr, S. A.; Horn, D. M.; Lindh, I.; McLafferty, F. W. Phosphopeptide/Phosphoprotein Mapping by Electron Capture Dissociation Mass Spectrometry. Anal. Chem. 2001, 73, 19-22.

47. Sze, S. K.; Ge, Y.; Oh, H. B.; McLafferty, F. W. Plasma Electron Capture Characterization of Large Dissociation for the Proteins by Top Down Mass Spectrometry. Anal. Chem. 2003, 75, 1599-1603.

48. Wu, S.; Yang, F.; Zhao, R.; Tolic, N.; Robinson, E. W.; Camp, D. G. Smith, R. D.; Pasa-Tolic, L. Integrated Workflow for Characterizing Intact Phosphoproteins from Complex Mixtures. Anal. Chem. 2009, 81, 4210-4219.

49. Young, J. B.; Li, L. Impulse-Driven Heated-Droplet Deposition Interface for Capillary and Microbore LC-MALDI MS and MS/MS. Anal. Chem. 2007, 79, 5927-5934.

50. Kjeldsen, F.; Savitski, M. M.; Nielsen, M. L.; Shi, L.; Zubarev, R. A. On Studying Protein Phosphorylation Patterns Using Bottom-up LC-MS/ MS: The Case of Human Alpha-Casein. Analyst 2007, 132, 768-776.

51. Poth, A. G.; Deeth, H. C.; Alewood, P. F.; Holland, J. W. Analysis of the Human Casein Phosphoproteome by 2-D Electrophoresis and MALDITOF/TOF MS Reveals New Phosphoforms. J. Proteome Res. 2008, 7 , 5017-5027.

52. Lee, B. S.; Krishnanchettiar, S.; Lateef, S. S.; Lateef, N. S.; Gupta, S Characterization of Oligosaccharide Moieties of Intact Glycoproteins by Microwave-Assisted Partial Acid Hydrolysis and Mass Spectrometry. Rapid Commun. Mass Spectrom. 2005, 19, 2629-2635.

53. Sandoval, W. N.; Arellano, F.; Arnott, D.; Raab, H.; Vandlen, R.; Lill, J. R. Rapid Removal of N-Linked Oligosaccharides Using Microwave Assisted Enzyme Catalyzed Deglycosylation. Int. J. Mass Spectrom. 2007, $259,117-123$

54. Warrand, J.; Janssen, H. G. Controlled Production of Oligosaccharides from Amylose by Acid-Hydrolysis under Microwave Treatment: Comparison with Conventional Heating. Carbohydr. Polym. 2007, 69, 353-362. 